\title{
Effects of Spinal Cord Stimulation in Patients with Chronic Nausea, Vomiting, and Refractory Abdominal Pain
}

\author{
Leonardo Kapural ${ }^{1}\left[\right.$ ] $\cdot$ Bradbury Kenneth Brown ${ }^{2} \cdot$ Shervin Harandi ${ }^{3} \cdot$ Jared Rejeski $^{4} \cdot$ Kenneth Koch $^{4}$
}

Received: 18 June 2020 / Accepted: 3 February 2021 / Published online: 23 February 2021

(c) The Author(s) 2021

\begin{abstract}
Background Patients with chronic nausea and vomiting often also have chronic abdominal pain. Spinal cord stimulation (SCS) may provide pain control, but scarce data are available regarding the effect of SCS on chronic nausea and vomiting. Aims We aimed to determine the effect of SCS in patients with chronic nausea, vomiting, and refractory abdominal pain. Methods Retrospective chart review of 26 consecutive patients who underwent SCS trial for a primary diagnosis of nausea, vomiting and refractory abdominal pain.

Results 26 patients underwent SCS trial, with an average age of 48 years. Twenty-three patients (88.5\%) reported $>50 \%$ pain relief during the temporary SCS trial and then underwent permanent implantation. Patients were then followed for 41 (22-62) months. At baseline, 20 of the 23 patients (87.0\%) reported daily nausea, but at 6 months and the most recent follow-up, only 8 (34.8\%) and 7 (30.4\%) patients, respectively, had daily nausea $(p<0.001)$. Days of nausea decreased from 26.3 days/month at baseline to 12.8 and 11.7 days/month at 6 months and at the most recent visit, respectively. Vomiting episodes decreased by 50\%. Abdominal pain scores improved from 8.7 to 3.0 and 3.2 at 6 months and the most recent visit, respectively (both $p<0.001$ ). Opioid use decreased from $57.7 \mathrm{mg}$ MSO4 equivalents to $24.3 \mathrm{mg}$ at 6 months and to $28.0 \mathrm{mg}$ at the latest patient visit (both $p<0.05$ ).

Conclusions SCS may be an effective therapy for long-term treatment of symptoms for those patients afflicted with chronic nausea, vomiting, and refractory abdominal pain.
\end{abstract}

Keywords Chronic nausea and vomiting $\cdot$ Chronic abdominal pain $\cdot$ Spinal cord stimulation $\cdot$ Gastric dysmotility

\section{Introduction}

There are many causes of nausea, a subjective symptom often accompanied by autonomic features, and therefore the diagnostic and therapeutic options are diverse. Additionally, nausea is frequently accompanied by vomiting and the combination of nausea and vomiting have marked deleterious effects on quality of life and are predictors of healthcare

Leonardo Kapural

lkapuralmd@gmail.com

1 Carolinas Pain Institute, 145 Kimel Park Drive, Suite 330, Winston Salem, NC 27103, USA

2 Department of Anesthesia, University of North Carolina at Chapel Hill, Chapel Hill, NC, USA

3 Modern Pain Management, Houston, TX, USA

4 Department of Internal Medicine, Section on Gastroenterology, Wake Forest Baptist Medical Center, Winston Salem, NC, USA utilization [1-4]. Despite the major quality of life impact of these symptoms, treatment of the symptoms can be difficult and the identification of the underlying causes may be challenging. Refractory abdominal pain in the setting of chronic nausea and vomiting is reported in gastroparesis and is similarly impactful with over one-third of patients reporting severe abdominal pain [5]. Because of the wellestablished gastrointestinal side effects of narcotic analgesics, management of this pain adds an additional layer of clinical complexity to an already difficult predicament [6].

A relationship between conventional spinal cord stimulation (SCS) and the enteric nervous system in abating visceral pain, nausea, and vomiting has been demonstrated [7]. The sympathetic nerves carry nociceptive information from the viscera to spinal nerve roots, which makes sympathetic pathways an appropriate target for SCS. In contrast, the parasympathetic vagal nerve afferents are carried in anterior and posterior trunks and are not amenable to SCS. Gastrointestinal (GI) motility is generally enhanced with the augmentation of 
vagal efferent nerve activity and inhibited by efferent sympathetic activity $[8,9]$. SCS decreases sympathetic activity by providing sympathovagal balance as measured by spectral analysis of heart rate variability [9]. These results suggest that a SCS-induced increase in GI motility might be attributed to the inhibition of sympathetic afferent and/or efferent activity with subsequent modulation of sympathovagal balance.

SCS as a treatment for chronic visceral pain with optimal lead placement for more consistent visceral pain relief was published in 2010 [10]. In that study, low-frequency SCS was delivered at the T4, T5, or T6 vertebral body levels with 1-3 leads placed in the midline position. Twenty-four patients reported at least $50 \%$ pain reduction, confirming that the splanchnic nerves, which are derived from the T5-12 segments, are an important stimulation target [10]. A subgroup in that patient cohort had gastroparesis and experienced a significant decrease in pain. In another study SCS improved pain scores and decreased opioid requirements in a cohort that included patients with gastroparesis and abdominal pain [11]. The present single-center, retrospective consecutive case study is intended to determine the effectiveness of SCS in improving symptoms in patients with chronic nausea, vomiting, and refractory abdominal pain. The effect on opioid use among this cohort was also studied.

\section{Methods}

After approval from the Institutional Review Board of the Forsyth Medical Center, electronic chart review was conducted in 26 consecutive patients with chronic nausea, vomiting, and refractory abdominal pain treated with SCS at the Carolinas Pain Institute, from January 1st of 2011 through January 1st 2018. Candidates were identified based on a computer-generated list from the database of patients who underwent SCS trial and had lingering nausea and vomiting despite gastroenterological evaluation with various therapeutic trials.

A data collection sheet was generated including patient age, gender, body mass index (BMI), a primary diagnosis of chronic nausea, vomiting, and refractory abdominal pain as documented by the referring provider. We performed a retrospective chart review to confirm prior evaluation and review four-hour solid-phase gastric emptying scintigraphy results, when available (Table 1). Gastroparesis was defined based on greater than $10 \%$ of the Eggbeaters meal remaining at four-hours during a gastric emptying scintigraphy test. Gastroparesis-like syndrome was defined based on symptoms consistent with gastroparesis (nausea, vomiting, early satiety, post-prandial bloating) without documented delayed gastric emptying. We documented the type of SCS system
Table 1 Baseline demographic data, clinical diagnosis, gastric emptying scintigraphy results, and type of spinal cord stimulator implanted

\begin{tabular}{llllll}
\hline Subject & Age & Gender & Clinical diagnosis & $\%$ Remaining at 4 h on GES & SCS type \\
\hline 1 & 71 & F & Gastroparesis-like & 7.7 & HF10-Nevro \\
2 & 36 & F & Gastroparesis-like & 9 & Traditional Medtronic \\
3 & 38 & F & Gastroparesis & 87 y & HF10-Nevro \\
4 & 52 & F & Gastroparesis & 21 & Traditional St. Jude \\
5 & 33 & F & Gastroparesis & 25 & Traditional St. Jude \\
6 & 54 & F & Gastroparesis & 22 & HF10-Nevro \\
7 & 43 & F & Gastroparesis & 64.9 & HF10-Nevro \\
8 & 51 & M & Gastroparesis & 48.8 & HF10-Nevro \\
9 & 38 & F & Gastroparesis & 19 & HF10-Nevro \\
10 & 43 & F & Gastroparesis & 18.8 & Traditional Medtronic \\
11 & 45 & F & Gastroparesis & Emesis during test & Traditional St. Jude \\
12 & 28 & F & Gastroparesis & 57 & Traditional St. Jude \\
13 & 60 & M & Gastroparesis & 47 & Traditional St. Jude \\
14 & 50 & F & Gastroparesis & 92 & Traditional St. Jude \\
15 & 32 & F & Gastroparesis-like & 1.4 & Traditional Medtronic \\
16 & 52 & M & Gastroparesis-like & 7.9 & HF10-Nevro \\
17 & 57 & F & Gastroparesis & 14 & HF10-Nevro \\
18 & 82 & F & Gastroparesis-like & 4 & HF10-Nevro \\
19 & 55 & M & Recurrent SBO & n/a & HF10-Nevro \\
20 & 52 & M & Gastroparesis & 27 & HF10-Nevro \\
21 & 72 & F & Chronic Pain & n/a & HF10-Nevro \\
22 & 50 & F & Chronic Pain & n/a & Traditional St. Jude \\
23 & 45 & F & Gastroparesis & 12.8 & Traditional St. Jude \\
\hline & & & & &
\end{tabular}


used as low frequency [40-90 Hz] (Trad-SCS) or high frequency [10 kHz] $(10 \mathrm{kHz}-\mathrm{SCS})$ and also recorded the length of SCS use per day. Pain scores (in visual analog scale [VAS]), frequency of nausea (days per month), and vomiting (events per month) were collected at baseline, approximately 6 months after implant, and during the patients last visit. In addition, the total amount of opiates taken before, at the 6-month interval, and during the latest visit was documented and converted to daily morphine sulfate (MSO4) equivalent in milligrams. Post-implant complications related to SCS, as well as patient satisfaction (Global Perceived Effect) and patient recommendation of the treatment to their relatives or friends were also recorded.

Complete electronic records of patients who underwent SCS trial for primarily nausea and vomiting were identified. If patients had a successful trial ( $>50 \%$ of pain relief), they subsequently received a permanent implant. While TradSCS system octrode leads were implanted within posterior epidural space based on paresthesia mapping, $10 \mathrm{kHz}-\mathrm{SCS}$ leads were always placed in the fluoroscopic midline position with the tip of the first lead at the top of the T4 vertebral body, and the second octrode was placed at the top of T5 vertebral body (Fig. 1a, b). Programming of either system was based on previously established manufacturer parameters and completed by an industry representative. In general, we used frequencies from 40 to $90 \mathrm{~Hz}$, pulse width 240-400 ms and amplitudes from 3 to $8 \mathrm{~mA}$ in all patients who received Trad-SCS. For $10 \mathrm{kHz}-\mathrm{SCS}$ parameters were unchanged at $10 \mathrm{kHz}$, pulse width of $30 \mathrm{~ms}$ and amplitudes from 2 to $7 \mathrm{~mA}$.

(a)

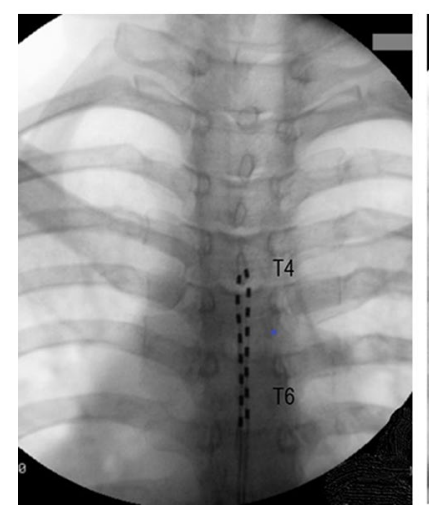

(b)

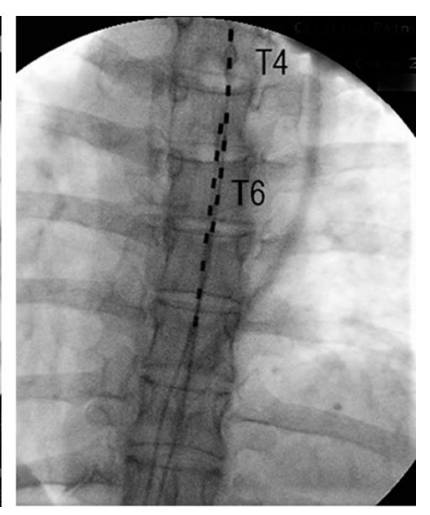

Fig. 1 Fluoroscopic anterior-posterior view of two different epidural lead placement configurations used in patients with chronic nausea, vomiting, and refractory abdominal pain. a Paresthesia-based placement of two parallel octrode leads at the T4 level. Traditional lowfrequency SCS elicited paresthesia responses covered abdominal area with concordant pain. b Two stacked electrode leads placed in fluoroscopically midline position with distal tip at top of T4 vertebral body (right lead) and T5 (left lead) used for high frequency $10 \mathrm{kHz}$ stimulation
Data are summarized using descriptive statistics for continuous variables. We used Student's paired $t$ tests to determine whether the VAS Scores attained following an implant of SCS were significantly different from baseline. We used Mann-Whitney Rank Sum Test to compare the two (independent) success rates for reducing pain intensity. A Fisher's exact test was used to compare differences in proportions of the number of days per month with nausea. All analyses and calculations were completed using Sigma Plot (San Jose, CA). Results are presented as mean ( \pm standard deviation, range, or $95 \% \mathrm{CI}$ is presented when indicated).

\section{Results}

Of 26 patients who underwent an SCS trial for the primary diagnosis of chronic nausea, vomiting, and refractory abdominal pain, 20 were women and six were men with an average age of $48.1\left(24-83 ; \mathrm{SD}_{ \pm} 16\right)$ years. Patients had a variety of diagnoses for their chronic nausea and vomiting, though primarily, they carried a diagnosis of gastric motility disorders: gastroparesis when gastric emptying tests were delayed or gastroparesis-like diagnosis when gastric emptying was normal or unknown (Table 1). Twenty-three patients had more than $50 \%$ pain relief during the temporary trial (17 women and six men) and therefore underwent formal SCS implant. Trad-SCS was implanted in 11 patients and $10 \mathrm{kHz}-\mathrm{SCS}$ was implanted in 12 patients. The 23 evaluated patients had an average age of $52.3(31-83 ; \mathrm{SD} \pm 13.1)$ years old with a baseline BMI of $27.0(15.1-38.5 ; \mathrm{SD} \pm 6.2)$ $\mathrm{kg} / \mathrm{m}^{2}$. These 23 patients had a mean post-implant followup period of 41 months (22-62; SD \pm 13$)$. All, except one (using Trad-SCS $14 \mathrm{~h}$ per day), used their SCS continuously for $24 \mathrm{~h}$ per day. There were no infections and no lead migrations requiring revision. Six patients had mild discomfort at the generator implantation site, one had moderate, and two experienced mild to moderate discomfort at the site of implantation.

Pain scores as measured by the VAS improved from $8.7 \pm 1.3 \mathrm{~cm}$ at baseline to $3.0 \pm 3.0 \mathrm{~cm}$ at 6 months $(p<0.001)$ and $3.2 \pm 3.1 \mathrm{~cm}$ at the last follow-up office visit $(p<0.001)$, see Fig. 2a. Pain scores in the subgroup of 12 patients implanted with $10 \mathrm{kHz}-\mathrm{SCS}$ improved from $8.4 \pm 1.2 \mathrm{~cm}$ at baseline to $2.6 \pm 3.3 \mathrm{~cm}$ at 6 months $(p<0.001)$ and $2.6 \pm 3.2 \mathrm{~cm}$ at the latest patient visit $(p<0.001)$, see Fig. 2b. Similarly, in the Trad-SCS group $(n=11)$, pain scores improved from $8.9 \pm 1.4 \mathrm{~cm}$ at baseline to $4.2 \pm 2.6 \mathrm{~cm}$ at 6 months $(p<0.001)$ and $3.8 \pm 3.0 \mathrm{~cm}$ at the most recent visit $(p=0.001)$. The individual pain reduction is shown in Fig. 3, with each bar representing the percent pain relief between baseline and follow-up of a single patient in the series. The overall responder rate was $73.9 \%$, with 17 of 23 patients achieving $>50 \%$ pain relief. 


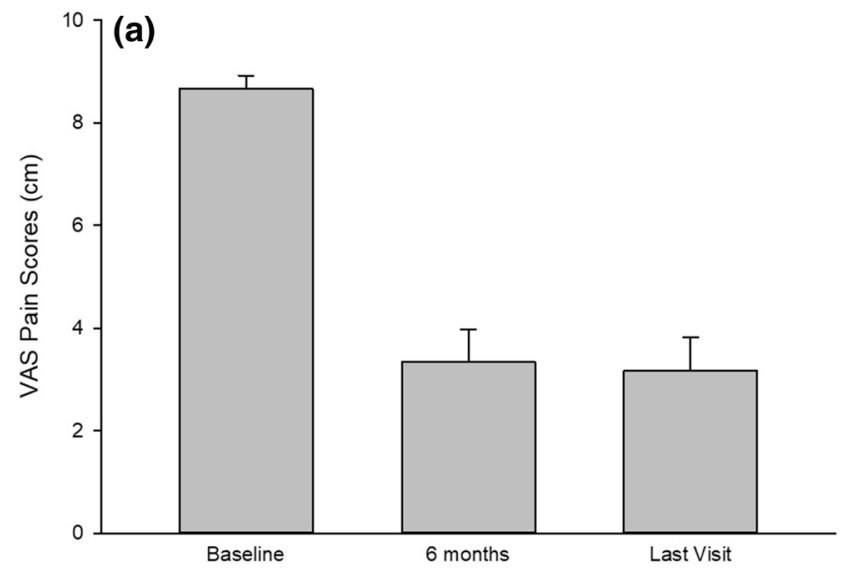

Fig. 2 a The average abdominal pain scores $( \pm$ SEM) from visual analog scale (VAS) with 0 indicting no pain and 10 indicating severe pain are shown at baseline, 6 months, and at the last patient visit after SCS implantation (last visit). Abdominal pain scores decreased significantly at 6 months and at the last patient visit compared with baseline $(p<0.001)(n=23)$. b Bar graph showing average abdomi-

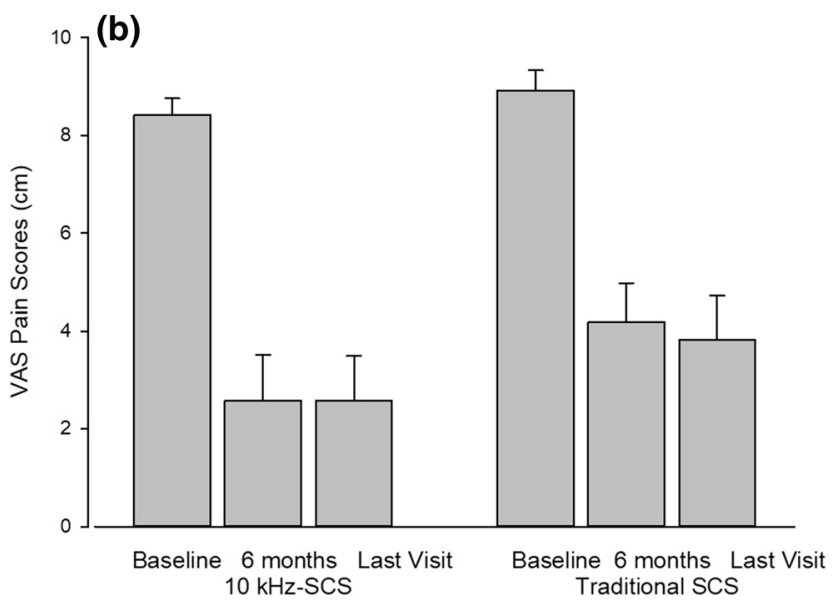

nal pain scores in the high frequency spinal cord stimulators $(10 \mathrm{kHz}$ SCS) group $(n=12)$ and the traditional low frequency spinal cord stimulators (Trad-SCS) group $(n=11)$. Abdominal pain decreased more in the $10 \mathrm{kHz}-\mathrm{SCS}$ group, but not statistically significant when compared with Trad-SCS group at 6 months and most recent visit (last visit) $(p>0.2)$ (a)

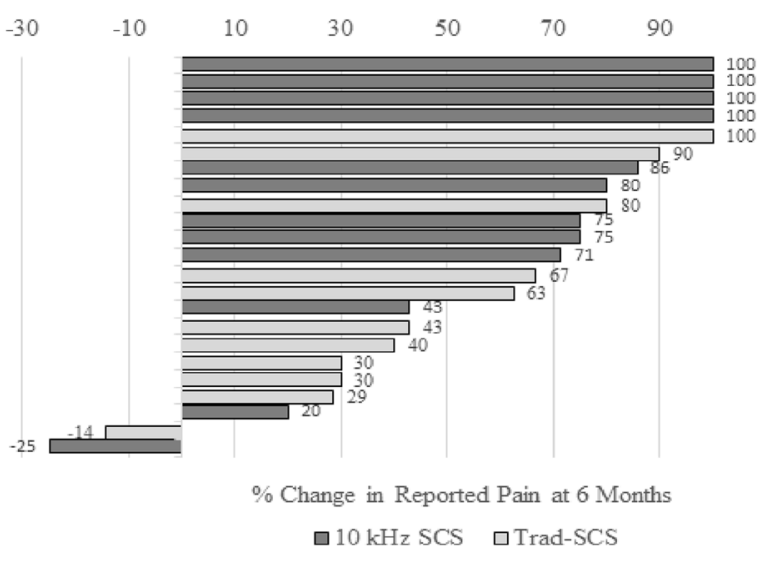

Fig. 3 Percent change in reported pain compared with baseline for each patient in the case series is shown at approximately 6 months after implant (a) and during the most recent visit (b). Responders were defined by achievement of greater than $50 \%$ pain relief. Over-

As displayed in Fig. 4a, opioid use at the baseline visit was 57.7 (95\% CI 34.3-81.0) mg of MSO4 equivalents per day with a range of zero to $180 \mathrm{mg}$. Sixteen patients $(69.5 \%)$ were taking $30 \mathrm{mg}$ or greater per day. Three patients did not take any opiates, and four patients were also on insignificant dosing of 4-8 MSO4 equivalents per day. There was a significant decrease in opioid use to an average of 24.3 (95\% CI 8.9-39.7) $\mathrm{mg}$ and 28.0 (95\% CI 12.3-43.8) $\mathrm{mg}$ at 6 months and at the last follow-up visit, respectively ( $p<0.006$ vs. baseline). Only nine patients (b)

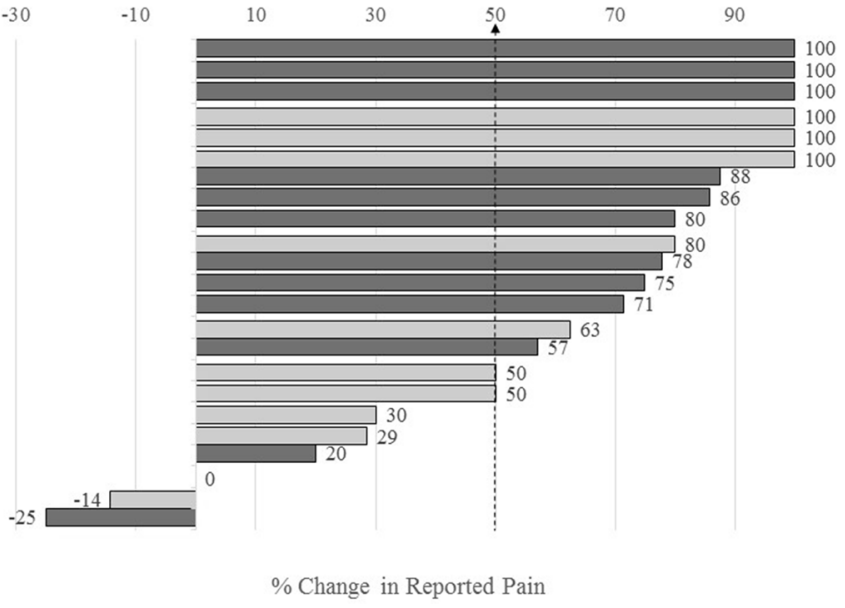

$\square 10 \mathrm{kHz}$ SCS $\square$ Trad-SCS

all, 17 of 23 patients were responders. Of the six non-responders, four were low frequency spinal cord stimulators (Trad-SCS) and two were high frequency spinal cord stimulators $(10 \mathrm{kHz}$ SCS $)$

were still receiving $30 \mathrm{mg}$ or more MSO4 equivalents at the last visit as opposed to 16 at baseline. No statistically significant difference was found between the patient cohorts in terms of mean MS04 equivalent dose at baseline or follow-ups, but the within group reduction was significant for the $10 \mathrm{kHz}-\mathrm{SCS}$ group ( $p=0.02$ at 6 months and $p=0.03$ at the last visit, respectively), but not for the TradSCS group ( $p=0.10$ at 6 months and $p=0.15$ at the last visit); see Fig. 4b. 


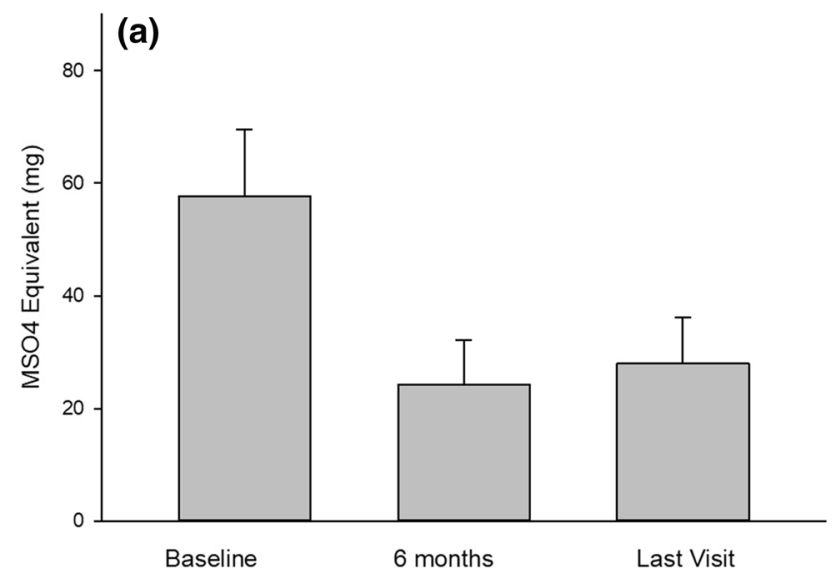

Fig. 4 a Long-term decrease in opioid use as measured in morphine milligram (MSO4 mg) equivalents with all spinal cord stimulator implantations (SCS). Overall reduction of opioid use was more than $50 \%$ at last follow-up ( $p=0.006$ vs. baseline) for all SCS. b Treatment with a high frequency spinal cord stimulator $(10 \mathrm{kHz}-\mathrm{SCS})$

As shown in Fig. 5a, 20 of 23 patients (87\%) experienced daily nausea at the baseline visit while only eight patients (35\%) experienced daily nausea at 6 months $(p=0.001)$ and only seven patients (30\%) had daily nausea at the last followup visit $(p<0.001)$. The number of days per month with nausea improved from $26.3 \pm 9.8$ per month at the baseline visit to $12.8 \pm 13.4$ and $11.7 \pm 13.0$ days at 6 months $(p<0.001)$ and at last recorded visit $(p<0.001)$ (Fig. 5b). Furthermore, the number of days of nausea per month was significantly less for $10 \mathrm{kHz}-\mathrm{SCS}$ than for Trad-SCS at both time points $(p=0.022$ at 6 months and $p=0.035$ at last recorded visit (Fig. 5c).

Eighty-seven percent of the patients reported being satisfied with their therapy and 15 patients reported the highest level of satisfaction; two patients reported the lowest satisfaction level. Twenty of 23 patients (87\%) indicated they would recommend this therapy to others with the same diagnosis.

\section{Discussion}

In this consecutive case series of patients with chronic nausea, vomiting, and refractory abdominal pain we describe, for the first time, the effects of SCS therapy on symptoms of nausea, vomiting, pain control, and opioid requirements. Significant improvements in abdominal pain, nausea and vomiting were durable with an average follow-up of approximately 3.5 years. Importantly, opioid use was decreased and patient satisfaction scores were encouraging. Our patients had thorough diagnostic evaluations to exclude specific mechanical or metabolic causes of symptoms. The majority

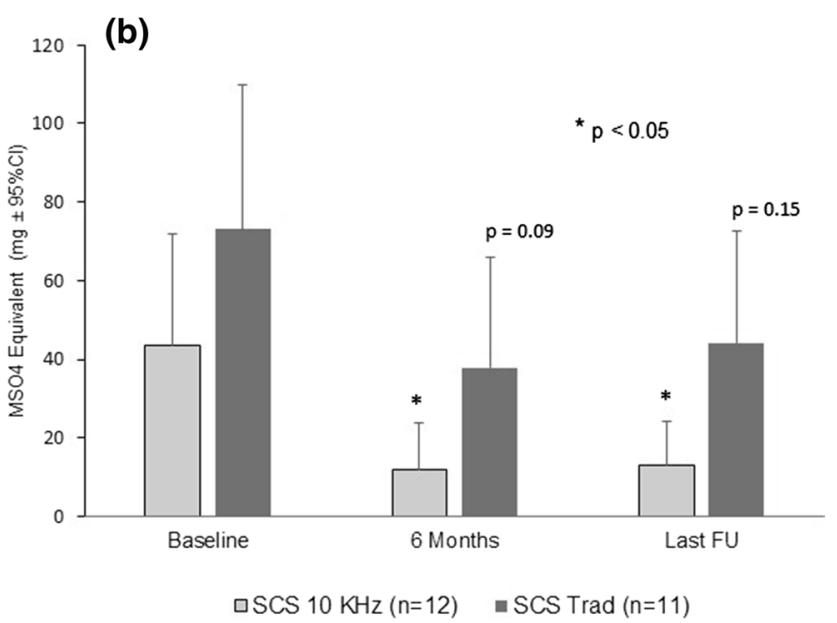

resulted in significant reduction in opioid use $(p<0.05)$ at followup visits, both 6 month and last follow-up (last FU), that was not recorded after treatment with low frequency spinal cord stimulators (Trad-SCS). There was no significant difference between $10 \mathrm{kHz}-\mathrm{SCS}$ and Trad-SCS in opioid use at baseline, or follow-ups

of patients had gastroparesis or gastroparesis-like symptoms; furthermore, medical therapies had failed to improve their symptoms. The combination of chronic nausea, vomiting, and refractory abdominal pain in patients with gastroparesis and gastroparesis-like symptoms and normal gastric emptying posits a significant management challenge given the paucity of effective therapies combined with the devastating toll these symptoms have on patients. Approximately twothirds of patients with gastroparesis experience moderateto-severe abdominal pain and this has a negative effect on their quality of life $[1,2,5]$. Our results suggest that SCS could prove to be an alternative to currently available drug or device therapies for patients with chronic nausea, vomiting, and refractory abdominal pain.

The marked improvement in patient reported symptoms of nausea, vomiting, and abdominal pain with SCS therapy is an important advance among this cohort composed primarily of patients with GI dysmotility. In addition, the significant reduction in opioid use is profound for several reasons. Opioids decrease motility throughout the gastrointestinal tract, delay gastric emptying, and act centrally to induce nausea and vomiting $[12,13]$. Opioid therapy in general has been linked to increased mortality in non-cancer pain syndromes, and thus strategies to mitigate opioid use among our patients are paramount [14]. Our findings suggest SCS treatment of nausea, vomiting and refractory abdominal pain has two beneficial actions: reducing symptoms and the need for opioids.

Gastric electrical stimulation (GES) is used with a humanitarian device exemption to treat symptoms associated with gastroparesis. The proposed mechanisms of action for GES include modulation of central and autonomic nervous 


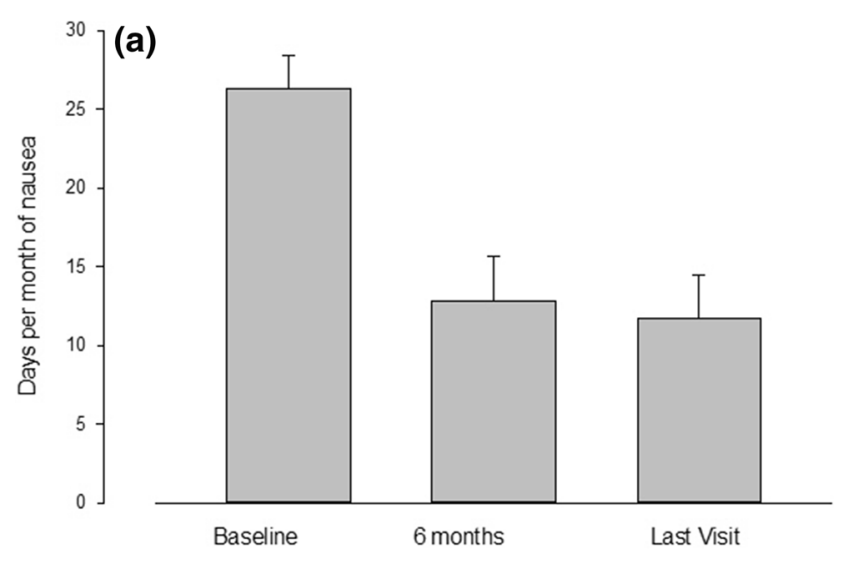

(c)

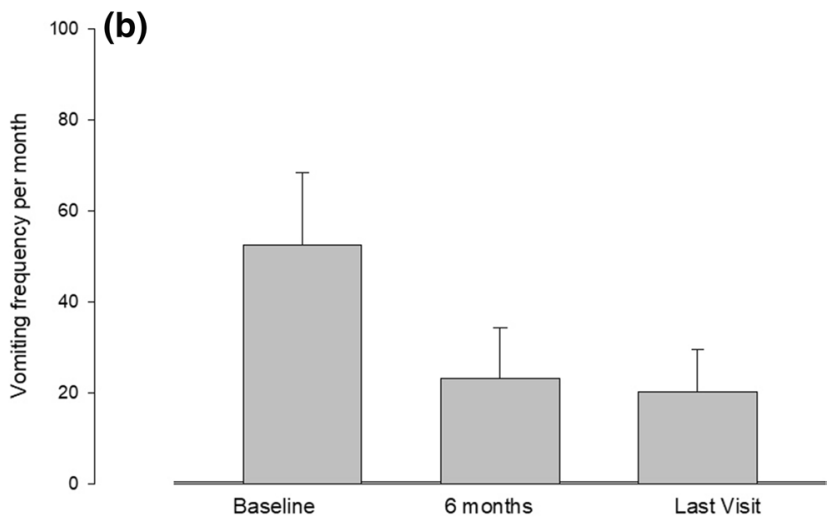

$p=0.022$

$p=0.035$

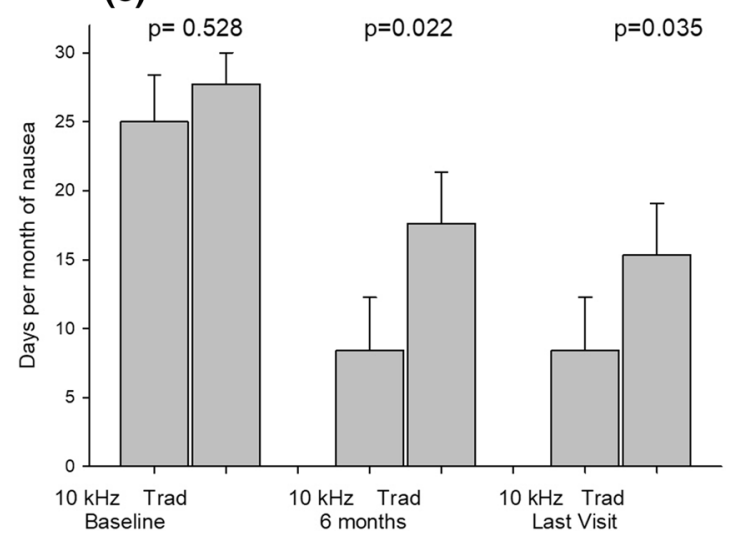

Fig. 5 Days per month of nausea (a) and vomiting frequency per month (b) at baseline, at 6 months, and the last visit after spinal cord stimulator implantation. The number of days per month of nausea and vomiting frequency per month decreased by $50 \%$ or more at 6 months post-implant and this effect persisted without significant difference to the last visit. c Days per month of nausea are shown in patients treated with high frequency spinal cord stimulators $(10 \mathrm{kHz})$ and low frequency spinal cord stimulators (Trad). Treatment with high frequency spinal cord stimulators resulted in significant reduction in days per month of nausea compared with low frequency spinal cord stimulators at 6 months $(p=0.022)$ and the last visit $(p=0.035)$ system activity, and fundic accommodation changes [1, 2, 7, 9-11]. However, the exact mechanism(s) of GES on refractory nausea and vomiting is unknown. SCS delivered at the high thoracic level, on the other hand, is known to suppress sympathetic outflow similar to sympathectomy involving blockade of superior hypogastric or celiac plexus $[15,16]$. SCS, for example, is associated with segmental and supraspinal down regulation of sympathetic outflow and is the mechanism of action of SCS treatment for intractable angina pectoris [17]. The effect of SCS on chronic abdominal pain and visceral hyperalgesia, at least in part, is attributed to segmental suppression of sympathetic outflow [18]. Furthermore, abdominal pain stimuli have been shown to slow gastric motility via sympathetic activation, and thus alleviating this pain and suppression of sympathetic outflow may have a beneficial effect on GI motility [19]. In our study, the $10 \mathrm{kHz}-\mathrm{SCS}$ showed significantly greater improvements in nausea and opioid usage and a trend toward a greater suppression of pain and vomiting compared with
Trad-SCS. The superior outcomes of $10 \mathrm{kHz}-\mathrm{SCS}$ compared with Trad-SCS may be related to more complete "sympathectomy" or greater modulation of the activity of dorsal horn neurons as suggested in rat and human studies [7, 20, 21]. It is unknown if the significant decrease in abdominal pain after SCS account for the decrease in nausea and vomiting symptoms or if pain, nausea, and vomiting pathways are affected separately. Either way, additional opioid sparring effect (see Fig. 4) seen here may contribute to an improvements in nausea and vomiting documented in our patients with painful dysmotility syndromes.

In addition to overall pain reduction, decreased opioid requirements, and "sympathectomy" SCS may manifest anti-nausea and anti-emetic properties through modulation of gastric physiology. A majority of these patients had gastroparesis, and while previous data on normalization of gastric emptying with interventions (i.e. gastric electrical stimulation versus gastric pacing) does not necessarily show that symptoms correlate with the rate of gastric emptying, 
improvement in fundic accommodation or gastric emptying would be important considerations [23]. Furthermore, treatment of gastroparesis and gastroparesis-like syndromes is challenging with a paucity of management options showing significant benefit over placebo; however, importantly, placebo effect in many therapeutic trials is rather robust [22, 23]. Thus, antinausea and antiemetic properties reported in patients receiving SCS may be partly attributable to placebo effect. As such, future and ongoing studies are planned to further evaluate the result of SCS on gastric emptying, capacity and myoelectrical activity.

In summary, SCS, and particularly $10 \mathrm{kHz}-\mathrm{SCS}$, is a minimally invasive and safe treatment modality showing excellent results in a cohort of challenging patients with chronic nausea, vomiting, and refractory abdominal pain, including those with gastroparesis and gastroparesis-like symptoms. Not only were pain scores and opioid use significantly reduced by SCS, but patients also reported a decrease in nausea and vomiting. These promising results are the basis to proceed with a prospective study of SCS in well-characterized patients with chronic nausea, vomiting, and abdominal pain with and without gastroparesis.

Author's contribution Dr. LK is the guarantor of the article. Dr. LK planned the study, conducted the study, collected and interpreted the data, and assisted with drafting of the manuscript. LK has approved the final draft. Dr. BB planned the study, collected the data, and assisted with drafting of the manuscript. BB has approved the final draft Dr. SH planned the study, collected the data, and assisted with drafting of the manuscript. SH has approved the final draft Dr. JR interpreted the data and assisted in drafting the manuscript. JR has approved the final draft. Dr. KK interpreted the data and assisted in drafting the manuscript. KK has approved the final draft.

Funding There was no funding nor study sponsors specific to this publication.

\section{Complaince with Ethical Standards}

Conflict of interest Dr. Leonardo Kapural reports the following: Research grants from Nevro, Medtronic, Saluda, Biotronik, SPR Therapeutics, Neuros, and Gimer; Consultant for: Nalu, Medtronic, Nevro, Abbott. Dr. Bradbury Brown reports no competing interests. Dr. Shervin Harandi is a Consultant for Nevro. Dr. Jared Rejeski reports no competing interests. Dr. Kenneth Koch reports no competing interests.

Open Access This article is licensed under a Creative Commons Attribution-NonCommercial 4.0 International License, which permits any non-commercial use, sharing, adaptation, distribution and reproduction in any medium or format, as long as you give appropriate credit to the original author(s) and the source, provide a link to the Creative Commons licence, and indicate if changes were made. The images or other third party material in this article are included in the article's Creative Commons licence, unless indicated otherwise in a credit line to the material. If material is not included in the article's Creative Commons licence and your intended use is not permitted by statutory regulation or exceeds the permitted use, you will need to obtain permission directly from the copyright holder. To view a copy of this licence, visit http://creativecommons.org/licenses/by-nc/4.0/.

\section{References}

1. Hasler WL, Wilson LA, Parkman HP, et al. Factors related to abdominal pain in gastroparesis: contrast to patients with predominant nausea and vomiting. Neurogastroenterol Motil 2013;25:427-438

2. Parkman HP, Yates K, Hasler WL, et al. Similarities and differences between diabetic and idiopathic gastroparesis. Clin Gastroenterol Hepatol 2011;9:1056-1064

3. De Boer-dennert M, De Wit R, Schmitz PI, et al. Patient perceptions of the side-effects of chemotherapy: the influence of 5HT3 antagonists. Br J Cancer 1997;76:1055-1061

4. Lacy BE, Crowell MD, Mathis C, Bauer D, Heinberg LJ. Gastroparesis: quality of life and health care utilization. J Clin Gastroenterol. 2018;52:20-24

5. Parkman HP, Wilson LA, Hasler WL, et al. Abdominal pain in patients with gastroparesis: associations with gastroparesis symptoms, etiology of gastroparesis, gastric emptying, somatization, and quality of life. Dig Dis Sci 2019;64:2242-2255. https://doi.org/10.1007/s10620-019-05522-9.

6. Camilleri M, Lembo A, Katzka DA. Opioids in gastroenterology: treating adverse effects and creating therapeutic benefits. Clin Gastroenterol Hepatol. 2017;15:1338-1349

7. Qin C, Farber JP, Linderoth B, Shahid A, Foreman RD. Neuromodulation of thoracic intraspinal visceroreceptive transmission by electrical stimulation of spinal dorsal column and somatic afferents in rats. JPain 2008;9:71-78

8. Tu L, Gharibani P, Yang Y, et al. A novel approach in spinal cord stimulation for enhancing gastric motility: a preliminary study on canines. J neurogastroenterol Motil 2020;26:147-159

9. Browning KN, Travagli RA. Central nervous system control of gastrointestinal motility and secretion and modulation of gastrointestinal functions. Compr Physiol 2014;4:1339-1368

10. Kapural L, Nagem H, Tlucek H, Sessler D. Spinal cord stimulation for chronic visceral abdominal pain. Pain Med 2010;11:347-355

11. Kapural L, Deer T, Yakovlev A, et al. Technical aspects of spinal cord stimulation for managing chronic visceral abdominal pain: the results from the National Survey. Pain Med 2010;11:685-691

12. Costello DJ, Borison HL. Naloxone antagonizes narcotic self-blockade of emesis in the cat. J Pharm Exp Therap 1977;203:222-230

13. Jeong ID, Camilleri M, Shin A, et al. A randomised, placebocontrolled trial comparing the effects of tapentadol and oxycodone on gastrointestinal and colonic transit in healthy humans. Aliment Pharm Therap 2012;35:1088-1096

14. Ray WA, Chung CP, Murray KT, Hall K, Stein CM. Prescription of long-acting opioids and mortality in patients with chronic noncancer pain. JAMA 2016;315:2415-2423

15. Steege JF. Superior hypogastric block during microlaparoscopic pain mapping. J Am Assoc Gynecol Laparosc 1998;5:265-267

16. Rauck RL. Sympathetic nerve blocks. In: Raj PP, ed. 2nd edn. St Louis: Mosby Year Book; 1992; 778-812.

17. Linderoth B, Foreman RD. Mechanisms of spinal cord stimulation in painful syndromes: role of animal models. Pain Med 2006; 7:S14-S26

18. Song GQ, Sun Y, Foreman RD, Chen JD. Therapeutic potential of spinal cord stimulation for gastrointestinal motility 
disorders: a preliminary rodent study. Neurogastroenterol Motil 2014;26:377-384

19. Sato A, Sato Y, Suzuki A, Uchida S. Neural mechanisms of the reflex inhibition and excitation of gastric motility elicited by acupuncture-like stimulation in anesthetized rats. Neurosci Res 1993;18:53-62

20. McMahon SB. Smith M. Effects of $10 \mathrm{KHz}$ Spinal Stimulation (I): Inhibition of Output Neurons of the Dorsal Horn. San Francisco, CA, Presented at Neuromodulation-The Science Meeting. 2016.

21. Lee KY, Bae C, Lee D, et al. Low-intensity, kilohertz frequency spinal cord stimulation differently affects excitatory and inhibitory neurons in the rodent superficial dorsal horn. Neuroscience 2020;428:132-139
22. Lal N, Livemore S, Dunne D, Khan I. Gastric Electrical Stimulation with the Enterra System: A Systematic Review. Gast Res Pract 2015;2015:762972

23. Shada A, Nielsen A, Marowski S, et al. Wisconsin's Enterra therapy experience: a multi-institutional review of gastric electrical stimulation for medically refractory gastroparesis. Surgery 2018;164:760-765

Publisher's Note Springer Nature remains neutral with regard to jurisdictional claims in published maps and institutional affiliations. 